ARTICLE

DOI: $10.1038 / s 41467-018-04876-4$

\title{
Southern Hemisphere westerlies as a driver of the early deglacial atmospheric $\mathrm{CO}_{2}$ rise
}

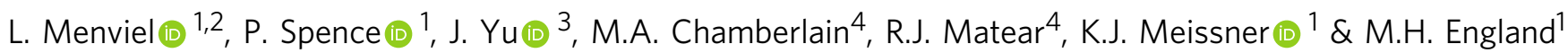

The early part of the last deglaciation is characterised by a $\sim 40 \mathrm{ppm}$ atmospheric $\mathrm{CO}_{2}$ rise occurring in two abrupt phases. The underlying mechanisms driving these increases remain a subject of intense debate. Here, we successfully reproduce changes in $\mathrm{CO}_{2}, \delta^{13} \mathrm{C}$ and $\Delta^{14} \mathrm{C}$ as recorded by paleo-records during Heinrich stadial 1 (HS1). We show that $\mathrm{HS}^{\mathrm{CO}_{2}}$ increase can be explained by enhanced Southern Ocean upwelling of carbon-rich Pacific deep and intermediate waters, resulting from intensified Southern Ocean convection and Southern Hemisphere (SH) westerlies. While enhanced Antarctic Bottom Water formation leads to a millennial $\mathrm{CO}_{2}$ outgassing, intensified $\mathrm{SH}$ westerlies induce a multi-decadal atmospheric $\mathrm{CO}_{2}$ rise. A strengthening of $\mathrm{SH}$ westerlies in a global eddy-permitting ocean model further supports a multi-decadal $\mathrm{CO}_{2}$ outgassing from the Southern Ocean. Our results highlight the crucial role of $\mathrm{SH}$ westerlies in the global climate and carbon cycle system with important implications for future climate projections.

\footnotetext{
${ }^{1}$ Climate Change Research Centre and ARC Centre of Excellence for Climate System Science, University of New South Wales, NSW 2052 Sydney, Australia. ${ }^{2}$ Department of Earth and Planetary Sciences, Macquarie University, NSW 2109 Sydney, Australia. ${ }^{3}$ Research School of Earth Sciences, The Australian National University, ACT 0200 Canberra, Australia. ${ }^{4}$ CSIRO Oceans and Atmosphere, ATAS 7004 Hobart, Australia. Correspondence and requests for materials should be addressed to L.M. (email: I.menviel@unsw.edu.au)
} 
$\mathrm{T}$ he natural climate variability of the last 800,000 years is dominated by glacial-interglacial cycles, with atmospheric $\mathrm{CO}_{2}$ variations providing a major positive feedback ${ }^{1}$. However, the sequence of events leading to deglacial $\mathrm{CO}_{2}$ rise remains poorly constrained and a combination of mechanisms has been invoked to explain the full $\sim 90 \mathrm{ppm}$ amplitude. These include reduced $\mathrm{CO}_{2}$ solubility, global ocean alkalinity decrease ${ }^{2}$, reduced iron fertilisation ${ }^{3-5}$, increased Southern Ocean ventilation $^{6,7}$ and poleward shift of the Southern Hemisphere (SH) westerlies ${ }^{8,9}$. Modelling studies trying to tackle the problem of glacial-interglacial $\mathrm{CO}_{2}$ changes mostly involve idealised sensitivity studies, often performed under constant preindustrial ${ }^{8,10-12}$ or LGM boundary conditions ${ }^{3,4}$. A detailed study of the deglaciation would provide a more direct link between changes in the climate and carbon cycle and would allow a direct model-data comparison, thus further constraining the processes responsible for atmospheric $\mathrm{CO}_{2}$ changes.

HS1 ( 17.6-14.7 ka), at the beginning of the last deglaciation, is an important period to understand as it represents a major phase of atmospheric $\mathrm{CO}_{2}$ rise and the transition out of the glacial period. Paleoproxy records suggest that North Atlantic Deep Water (NADW) formation weakened significantly during $\mathrm{HS}^{13}$, effectively reducing the meridional heat transport to the North Atlantic and leading to cold and dry conditions over Greenland ${ }^{14}$ and the North Atlantic ${ }^{15}$. In contrast, paleoproxies indicate that Antarctic surface air temperature and Southern Ocean surface waters experienced a warming of $\sim 5^{\circ} \mathrm{C}$ and $\sim 3^{\circ} \mathrm{C}^{16,17}$, respectively. This warming is partly due to increased heat content in the South Atlantic, subsequent advection of warm waters through the Antarctic Circumpolar Current and the concurrent $40 \mathrm{ppm}$ atmospheric $\mathrm{CO}_{2}$ increase. However, the mechanisms leading to $\mathrm{HS} 1 \mathrm{CO}_{2}$ rise are still poorly constrained and an overarching mechanism linking this $\mathrm{CO}_{2}$ rise to the North Atlantic cooling and high southern latitude warming is still missing.

Recent high-resolution Antarctic ice core records ${ }^{7,18,19}$ show that atmospheric $\mathrm{CO}_{2}$ rose in two major phases at $\sim 17.2$ and $\sim 16.2 \mathrm{ka}$, each associated with a $\sim 0.2 \%$ o decrease in the atmospheric carbon isotopic composition $\left(\delta^{13} \mathrm{CO}_{2}\right)$. In addition, atmospheric radiocarbon content $\left(\Delta^{14} \mathrm{C}\right)$ declined by $\sim 112 \%$ between 17.6 and $15 \mathrm{ka}^{20}$. Explaining the atmospheric $\mathrm{CO}_{2}$ increase thus also requires attributing the concurrent $\delta^{13} \mathrm{CO}_{2}$ and $\Delta^{14} \mathrm{C}$ declines. $\delta^{13} \mathrm{CO}_{2}$ integrates changes in terrestrial carbon, marine export production, oceanic circulation, and air-sea gas exchange ${ }^{21}$, while $\Delta^{14} \mathrm{C}$ is controlled by atmospheric ${ }^{14} \mathrm{C}$ production and carbon exchange between the atmosphere and abyssal ocean carbon or old terrestrial carbon.

A number of processes have been put forward to explain the early deglacial atmospheric $\mathrm{CO}_{2}$ increase. Co-variations of iron flux and nutrient utilisation in the sub-Antarctic ${ }^{5}$ suggest that iron fertilisation could exert a significant control on atmospheric $\mathrm{CO}_{2}$ during $\mathrm{HS} 1$ through its modulation of the Southern Ocean biological pump efficiency. Modelling studies show that reduced iron fertilisation could lead to a millennial atmospheric $\mathrm{CO}_{2}$ increase of $\sim 10 \mathrm{ppm}$ coupled with a $0.1 \% \delta^{13} \mathrm{CO}_{2}$ decrease ${ }^{3,4,19,22}$, during the early deglaciation. However, iron fertilisation does not affect atmospheric $\Delta^{14} \mathrm{C}$ or ocean ventilation ages, and variations in atmospheric iron deposition to the Southern Ocean are ultimately controlled by the exposure of the continental shelves, SH hydrology and winds. Indeed, a deglacial decline in South Atlantic ventilation ages has been observed ${ }^{6}$, indicating a possible role of Southern Ocean ventilation in driving the deglacial $\mathrm{CO}_{2}$ increase. This change in Southern Ocean ventilation could be modulated by the strength and position of the $\mathrm{SH}_{\text {westerlies }}{ }^{7-9}$. Idealised modelling studies performed under constant pre-industrial conditions have shown that stronger or poleward shifted $\mathrm{SH}$ westerlies could enhance deep ocean ventilation thereby leading to an atmospheric $\mathrm{CO}_{2}$ rise and $\delta^{13} \mathrm{CO}_{2}$ decline ${ }^{10,11,21}$. While all numerical experiments performed show that stronger $\mathrm{SH}$ westerlies lead to an atmospheric $\mathrm{CO}_{2}$ increase ${ }^{10,11,21,23}$, the impact of changes in their latitudinal position is more ambiguous and could depend on their initial latitudinal position 23,24 . However, the latitudinal position of the $\mathrm{SH}$ westerlies at the LGM remains unclear ${ }^{25,26}$. In addition, a recent modelling study ${ }^{12}$, also performed under constant preindustrial boundary conditions, concluded that the $\mathrm{SH}$ westerlies did not lead to significant changes in atmospheric $\mathrm{CO}_{2}$ during HS1. Instead, and even though no abrupt atmospheric $\mathrm{CO}_{2}$ rise was simulated, the conclusion was that the HS1 atmospheric $\mathrm{CO}_{2}$ rise was solely due to a reduced efficiency of the biological pump, resulting from a weaker Atlantic Meridional Overturning Circulation.

As the magnitude and rate associated with an oceanic carbon release to the atmosphere during the deglaciation have been questioned, a deglacial transfer of carbon from the terrestrial to atmospheric reservoir has been put forward, either as thawing of Northern Hemisphere permafrost ${ }^{27}$ during HS1, or as a Northern Hemisphere terrestrial carbon release due to a southward shift of the Intertropical Convergence Zone (ITCZ) at $16.2 \mathrm{ka}^{19,28}$. However, the global terrestrial carbon reservoir increased over the deglaciation ${ }^{29,30}$ and the timing and magnitude of the permafrost carbon contribution remain poorly constrained.

So far, no three-dimensional transient simulation was able to reproduce the changes in atmospheric $\mathrm{CO}_{2}$, its isotopic composition, as well as oceanic $\delta^{13} \mathrm{C}$ and ventilation ages across HS1. Here, we explore the processes leading to the two-stage $\mathrm{CO}_{2}$ increase during HS1, and their links to NADW weakening and Antarctic warming by performing a suite of transient experiments of HS1 with the carbon-isotopes enabled Earth System Model LOVECLIM $^{21}$. This suite of simulations assesses the impact of Southern Ocean ventilation changes, including the potential role of buoyancy and dynamic forcing, such as meltwater and $\mathrm{SH}$ westerlies, in driving the rapid atmospheric $\mathrm{CO}_{2}$ increase during HS1. The ocean carbon response to changes in SH westerlies is further assessed in a global eddy-permitting ocean model. We show that enhanced Southern Ocean convection and upwelling of Circumpolar Deep Water, driven by intensified $\mathrm{SH}$ westerlies, lead to an atmospheric $\mathrm{CO}_{2}$ rise, $\delta^{13} \mathrm{CO}_{2}$ and $\Delta^{14} \mathrm{C}$ decrease in agreement with paleo-records $s^{7,19,20}$.

\section{Results}

Simulating atmospheric $\mathrm{CO}_{2}$ and $\delta^{13} \mathrm{CO}_{2}$ during HS1. The transient simulation is initialised from a Last Glacial Maximum (LGM) state constrained by oceanic $\delta^{13} \mathrm{C}$ and ventilation age distributions ${ }^{31}$. The LGM ocean circulation is characterised by shallow NADW, relatively weak North Pacific Intermediate Water (NPIW) and very weak Antarctic Bottom Water (AABW), obtained by adding a meltwater flux into the Southern Ocean and weakening the $\mathrm{SH}$ windstress by $20 \%{ }^{31}$. By forcing the model with changes in orbital parameters, Northern Hemisphere icesheet extent and albedo as well as freshwater input in the North Atlantic (Methods), the deep ocean convection in the Norwegian Sea is suppressed, thus resulting in very weak NADW formation during HS1 (Fig. 1a). Reduced moisture transport from the Atlantic to the Pacific and a deepening of the Aleutian low due to NADW cessation leads to stronger NPIW formation in agreement with paleoproxy records ${ }^{32,33}$ (Fig. 1j).

The NADW weakening induces a southward shift of the ITCZ (Fig. 2, Supplementary Figs. 1 and 2) via reduced meridional heat transport to the North Atlantic. Modelling studies ${ }^{34,35}$ have shown that this ITCZ shift could weaken the SH Hadley cell and strengthen the subtropical jet, which in turn would shift the 

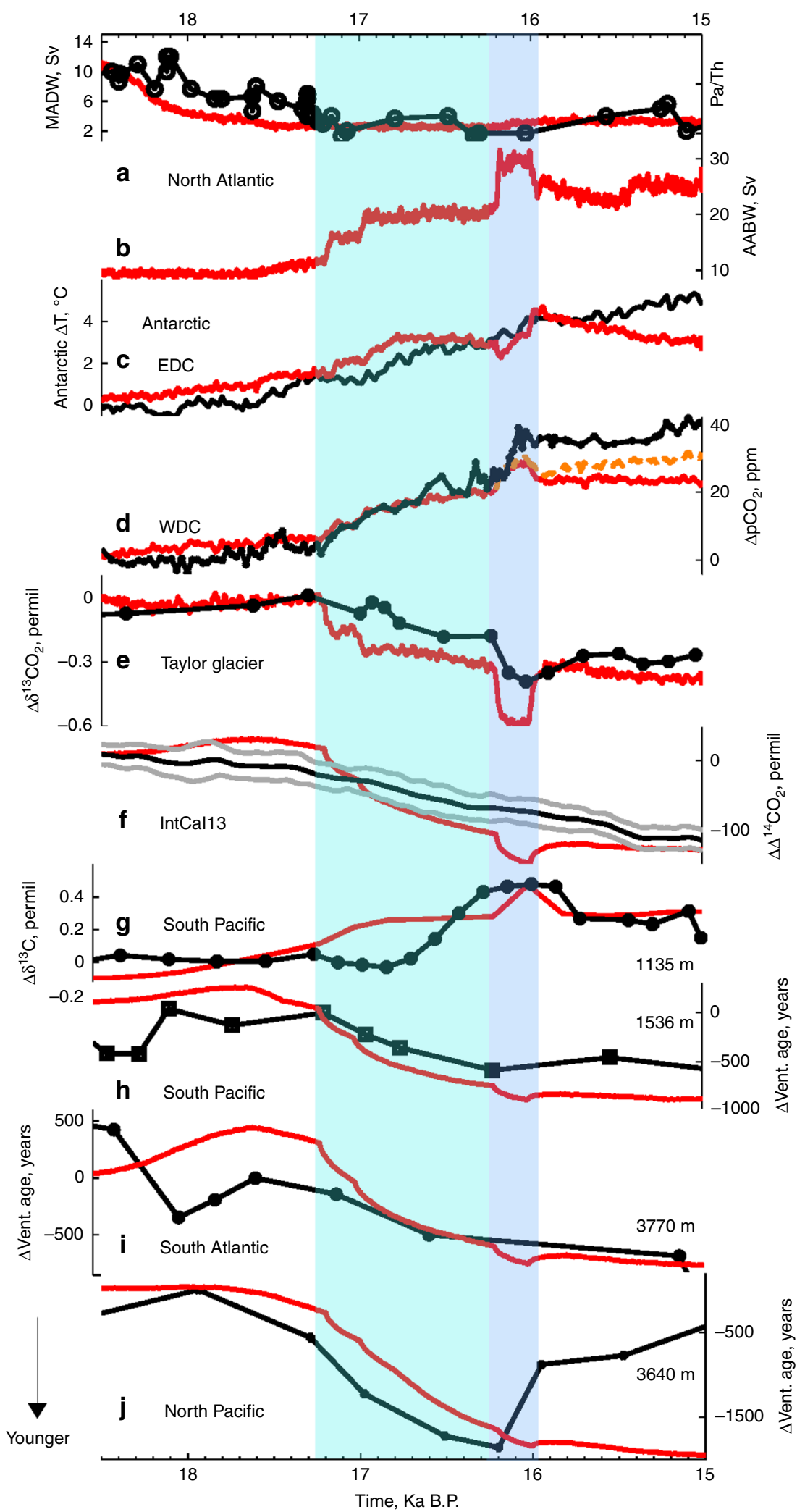

Fig. 1 Model-paleodata comparison across HS1. Time evolution of selected paleo records across HS1 (black) compared to the results of a transient simulation (red, LH1-SO-SHW). a North Atlantic $\mathrm{Pa} / \mathrm{Th}^{81}$ and simulated NADW transport; b AABW transport; $\mathbf{c}$ Antarctic air temperature ${ }^{16}$; d Atmospheric $\mathrm{pCO}_{2}{ }^{7}$ on the WD2O14 chronology ${ }^{82} ; \mathbf{e} \delta^{13} \mathrm{CO}_{2}{ }^{19}$ on the WD2O14 chronology ${ }^{82} ; \mathbf{f} \Delta^{14} \mathrm{CO}_{2}{ }^{20} ; \mathbf{g} \delta^{13} \mathrm{C}$ anomalies averaged over the intermediate South Pacific (170-180 $\left.{ }^{\circ} \mathrm{E}, 40-30^{\circ} \mathrm{S}, 1007-1443 \mathrm{~m}\right)$ and compared to a benthic $\delta^{13} \mathrm{C}$ record ${ }^{55}$; Ventilation age anomalies from $\mathbf{h}$ the intermediate South Pacific $75^{\circ} \mathrm{W}-50^{\circ} \mathrm{W}, 44^{\circ} \mathrm{S}-48^{\circ} \mathrm{S}, 1443-1992 \mathrm{~m}^{38}$, i the deep South Atlantic $14^{\circ} \mathrm{W}-8^{\circ} \mathrm{W}, 40^{\circ} \mathrm{S}-48^{\circ} \mathrm{S}, 3300-4020 \mathrm{~m}{ }^{6}$ and $\mathbf{j}$ the deep North Pacific $152^{\circ} \mathrm{W}-147^{\circ} \mathrm{W}, 51^{\circ} \mathrm{N}-57^{\circ} \mathrm{N}, 3300-4020 \mathrm{~m}^{33}$. EDC and WDC, respectively, stand for EPICA Dome C and West Antarctic Ice Sheet Divide ice cores. 5-21 years moving average are shown for all the simulated variables except for $\Delta^{14} \mathrm{CO}_{2}$ and the oceanic ventilation ages to filter the high-frequency variability. The dashed orange line in $\mathbf{d}$ includes a global ocean alkalinity decrease of $-6 \mu \mathrm{mol} \mathrm{L}^{-1}$ per 1000 years 


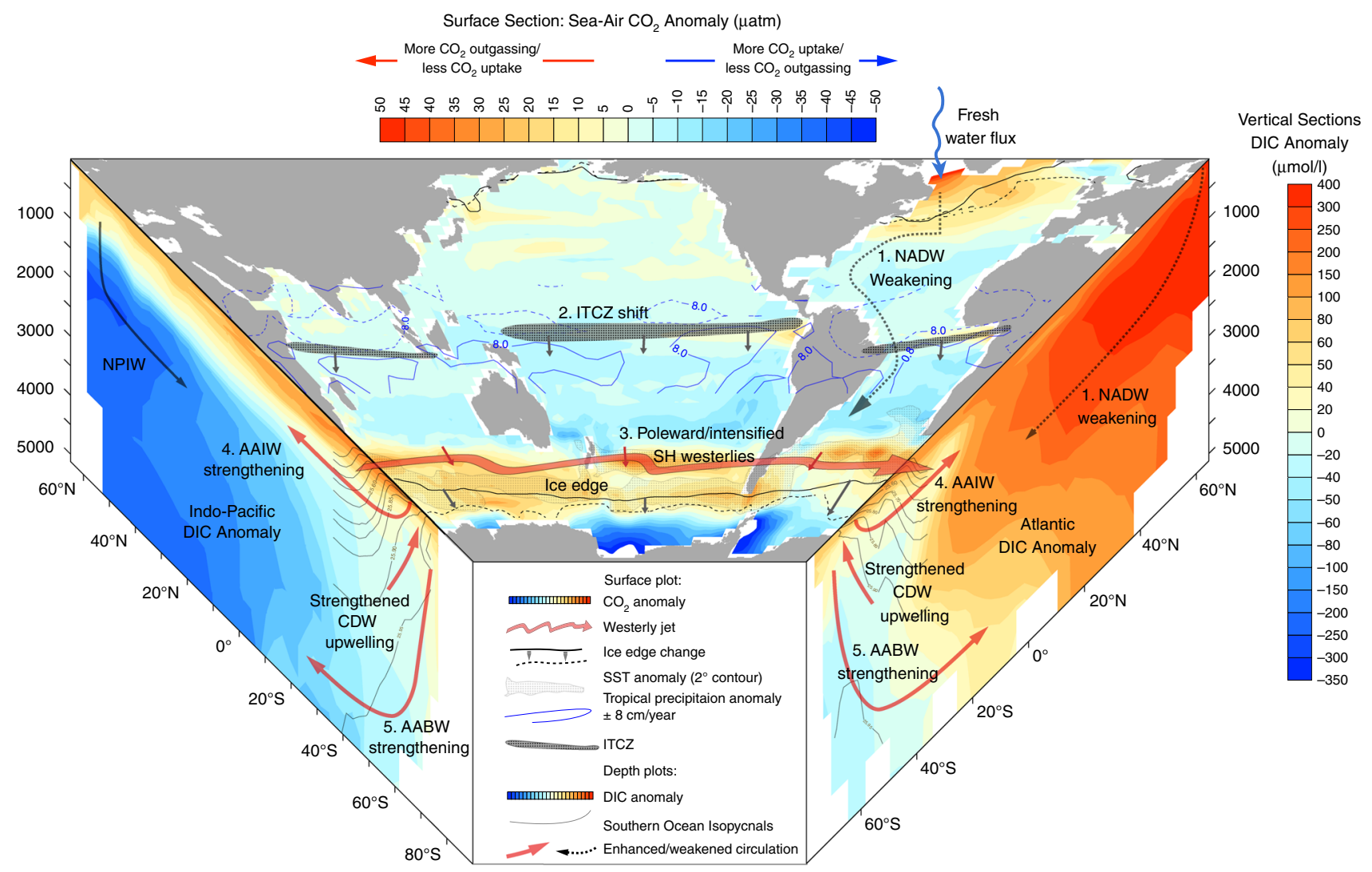

Fig. 2 Sequence of events leading to a $\mathrm{pCO}_{2}$ rise and initiation of the deglaciation. Results of experiment LH1-SO-SHW (as shown in Fig. 1) at 16 ka and compared to $19 \mathrm{ka}$. (Top centre panel) Sea-air $\mathrm{pCO}_{2}$ anomalies ( $\mu \mathrm{atm}$ ), with positive values indicating a potential $\mathrm{CO}_{2}$ flux out of the ocean (Southern Ocean) or reduced $\mathrm{CO}_{2}$ uptake (North Atlantic). Overlaid are tropical precipitation anomalies (blue contour lines, $\pm 8 \mathrm{~cm} \mathrm{yr}^{-1}$ ), Southern Ocean SST anomalies (grey dots indicate an area with $\Delta \mathrm{SST} \geq 2{ }^{\circ} \mathrm{C}$ ), and the $0.1 \mathrm{~m}$ austral summer sea-ice contour (19 ka, solid black and $16 \mathrm{ka}$, dashed black lines). (Side panels) DIC anomalies zonally averaged over the (left) Indo-Pacific and (right) Atlantic basins. Southern Ocean isopycnals at 16 ka are overlaid (grey contours, $0.05 \mathrm{~kg} \mathrm{~m}^{-3}$ ). 1. NADW cessation cools the North Atlantic and warms the South Atlantic, thus 2. shifting the ITCZ southward, 3. which strengthens/shifts the SH westerlies (SHW) poleward, 4. thus enhancing the upwelling of Circumpolar Deep Water (CDW) on a decadal timescale. 5. Polar/intensified SHW enhances deep ocean convection, leading to a centennial-scale Southern Ocean $\mathrm{CO}_{2}$ outgassing and mid/high southern latitude warming

eddy-driven jet poleward and strengthen the $\mathrm{SH}$ westerlies by $\sim 25 \%$. To include this atmospheric teleconnection between the tropics and the high southern latitudes, which is not well represented in our coarse resolution atmospheric model, the $\mathrm{SH}$ westerlies are artificially strengthened from their LGM state commencing at $17.2 \mathrm{ka}$ (Methods, simulation LH1-SO-SHW). This timing of $17.2 \mathrm{ka}$ corresponds, within dating uncertainties, to the Bermuda Rise ${ }^{231} \mathrm{~Pa} /{ }^{230} \mathrm{Th}$ record reaching maximum values $^{13}$, thus indicating very weak NADW transport. However, another phase of NADW weakening ${ }^{36}$, probably associated with the disintegration of the Laurentide ice-sheet and Heinrich event 1 , occurred at $\sim 16.2 \mathrm{ka}^{37}$. A further intensification of the $\mathrm{SH}$ westerlies and reduced Southern Ocean freshwater flux at $16.2 \mathrm{ka}$ enhances Southern Ocean convection in our simulation, resulting in stronger Antarctic Intermediate Water (AAIW) and AABW formation during HS1 (Fig. 3d, e), consistent with reduced ventilation ages in the South Atlantic ${ }^{6}$ and the Pacific ${ }^{38}$ (Fig. 1h, i) as well as a peak in the Southern Ocean opal flux'.

Enhanced formation of AAIW and AABW and the associated upwelling of Circumpolar Deep Water decrease the oceanic carbon content below $\sim 2000 \mathrm{~m}$ depth and particularly in the deep South Pacific, leading to $\mathrm{CO}_{2}$ outgassing in the Southern Ocean (Fig. 2). As a result, the simulated atmospheric $\mathrm{CO}_{2}$ increases in close agreement with high-resolution Antarctic ice core records (Fig. 1d) ${ }^{7}$, with a simulated $19 \mathrm{ppm} p \mathrm{CO}_{2}$ increase between 17.2 and $16.2 \mathrm{ka}$ and an abrupt $9 \mathrm{ppm}$ rise at $16.2 \mathrm{ka}$. Over the course of the experiment the global ocean carbon content decreases by $\sim 100 \mathrm{GtC}$, while the terrestrial carbon content increases by $\sim 50$ GtC (Fig. 3g red line, Supplementary Table 1). This terrestrial carbon increase is mostly due to enhanced carbon storage in vegetation, roots and soils of the southern tropics due to a southward shift of the ITCZ, and the fertilisation effect linked to the atmospheric $\mathrm{CO}_{2}$ increase (Supplementary Fig. 1).

In line with ice core records ${ }^{19}$, each phase of atmospheric $\mathrm{CO}_{2}$ rise is associated with $\sim 0.25 \%{ }^{13} \mathrm{CO}_{2}$ decrease (Fig. 1e). Each of these drops in $\delta^{13} \mathrm{CO}_{2}$ is however $\sim 0.05 \%$ higher than the ones recorded in ice-core records, thus leading to a significant overshoot at $\sim 16 \mathrm{ka}$. These $\delta^{13} \mathrm{CO}_{2}$ decreases are primarily due to enhanced ventilation of deep and intermediate waters with low $\delta^{13} \mathrm{C}$ signatures and upwelling in the Southern Ocean (Fig. 4a, b) 21 . This reduces the respired oceanic carbon content (Supplementary Fig. 3) and results in positive $\delta^{13} \mathrm{C}$ anomalies along the AAIW and AABW pathways, as recorded in benthic $\delta^{13} \mathrm{C}$ (Fig. 4a, b, Supplementary Table 2). During HS1, ventilation of "old" deep waters decreases atmospheric $\Delta^{14} \mathrm{C}$ by $\sim 150 \%$, consistent with atmospheric $\Delta^{14} \mathrm{C}^{20}$ and marine $\Delta^{14} \mathrm{C}$ reconstructions ${ }^{6,32,33,38}$ (Fig. 1f,h-j and $4 \mathrm{c}$, d, Supplementary Fig. 4).

Finally, due to the concurrent atmospheric $\mathrm{CO}_{2}$ rise and enhanced meridional heat transport towards high southern 

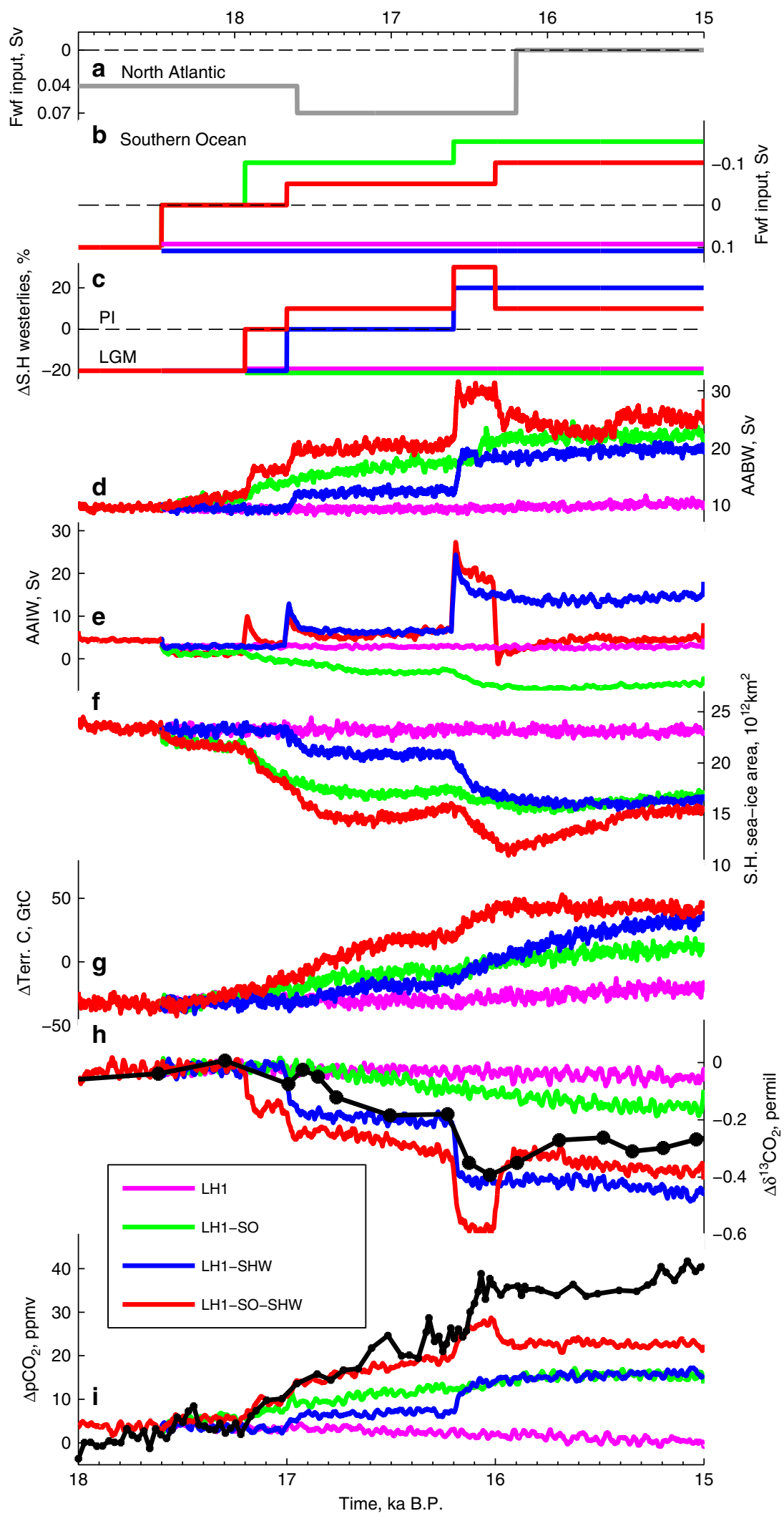

Fig. 3 Summary of transient experiments. Timeseries of freshwater input into a the North Atlantic and $\mathbf{b}$ the Southern Ocean and $\mathbf{c}$ SH westerly wind forcing. Simulated $\mathbf{d} \mathrm{AABW} ; \mathbf{e} \mathrm{AAIW} ; \mathbf{f} \mathrm{SH}$ sea-ice area; $\mathbf{g}$ terrestrial carbon reservoir anomalies with respect to $19 \mathrm{ka}$ (Supplementary $\mathrm{Table} 1$ ); $\mathbf{h} \Delta \delta^{13} \mathrm{CO}_{2}$ and $\mathbf{i} \Delta p \mathrm{CO}_{2}$; for all transient experiments (colour). 5-21 years moving average are shown for all the variables except for the terrestrial carbon to filter the high-frequency variability. WDC $p \mathrm{CO}_{2}{ }^{7}$ and Taylor Glacier $\delta^{13} \mathrm{CO}_{2}{ }^{19}$ are shown in black 


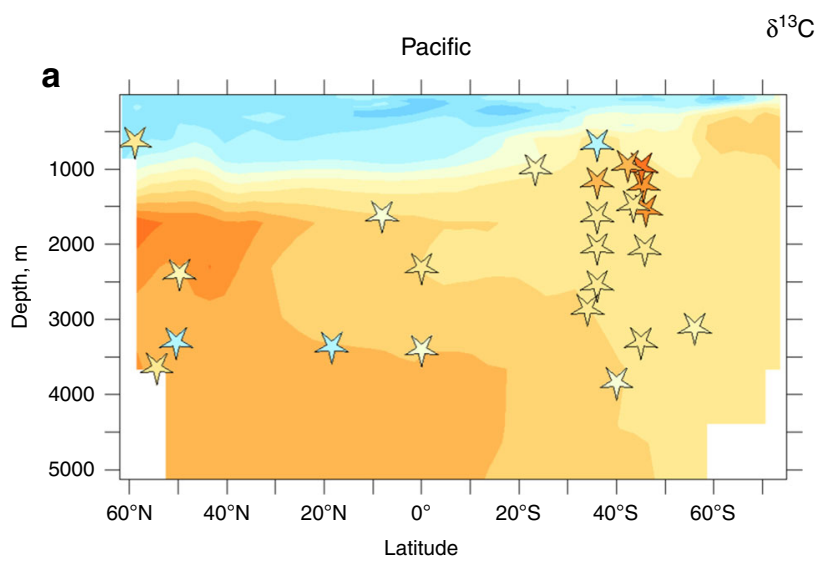

$\delta^{13} \mathrm{C}$ anomalies (\%)

Atlantic

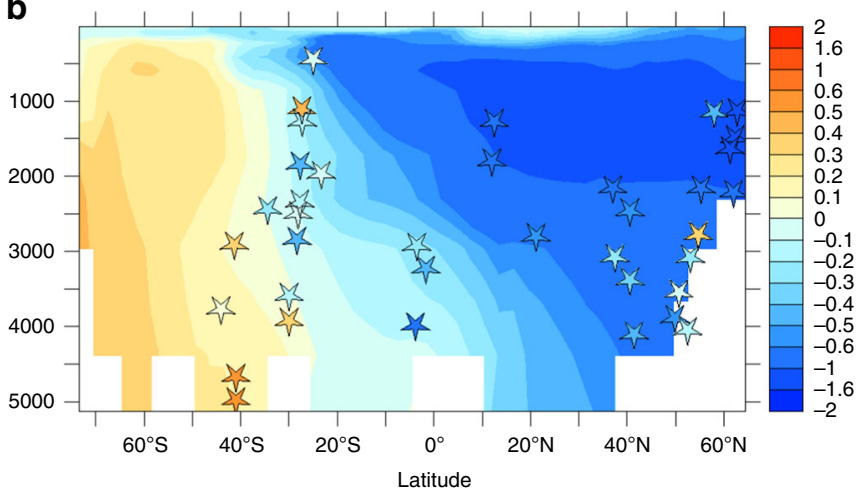

Ventilation age anomalies (years)
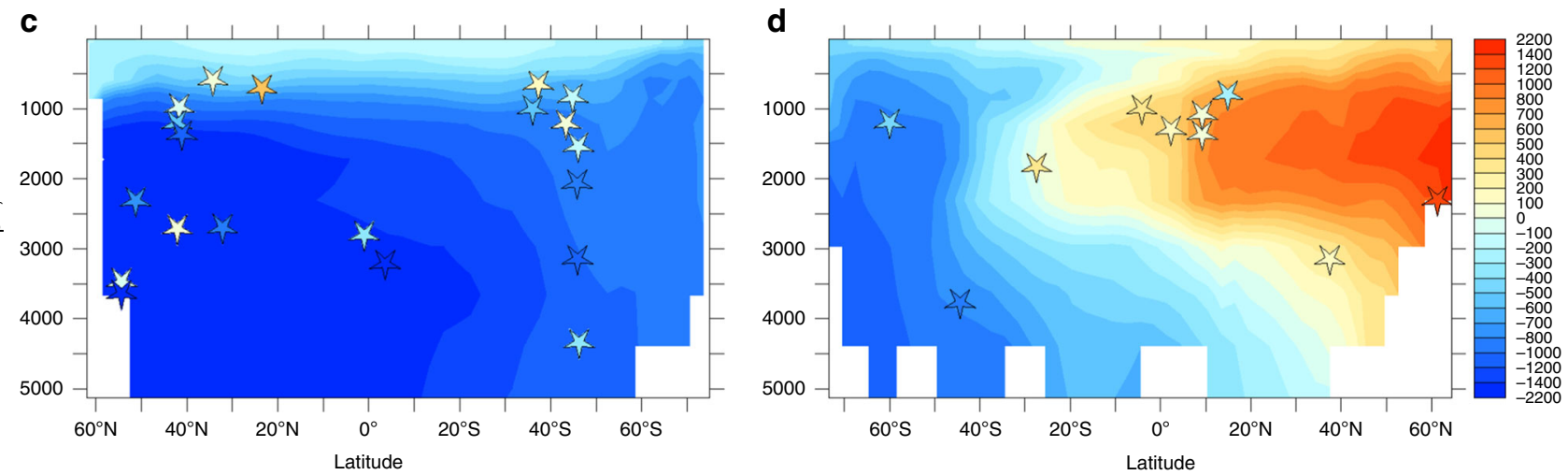

Fig. 4 Ocean carbon isotopes. Simulated $\mathbf{a}, \mathbf{b} \delta^{13} \mathrm{C}(\%$ o) and $\mathbf{c}, \mathbf{d}$ ventilation ages anomalies (years) at 16 ka compared to 19 ka, zonally averaged over $\mathbf{a}, \mathbf{c}$ the Pacific and $\mathbf{b}$, $\mathbf{d}$ the Atlantic in experiment LH1-SO-SHW. Stars represent paleodata estimates: $\mathbf{a}$, b benthic $\delta^{13} \mathrm{C}$ anomalies $(R=0.77, p=0.01$, Supplementary Table 2$)$ and $\mathbf{c}$, $\mathbf{d}$ ventilation ages anomalies $(R=0.52, p=0.01$, Supplementary Table 3)

latitudes, Southern Ocean sea surface temperature (SST) and Antarctic air temperature increase by up to $3{ }^{\circ} \mathrm{C}$ and $4{ }^{\circ} \mathrm{C}$, respectively, between $17.6 \mathrm{ka}$ and $15 \mathrm{ka}$, and the Southern Ocean sea-ice cover is significantly reduced (Figs. 1c, 2 and $3 \mathrm{f}$ red line). This is in agreement with idealised experiments performed with a global eddy-permitting coupled ocean sea-ice model, which shows that stronger AABW induces a Southern Ocean SST increase through enhanced poleward heat transport ${ }^{39}$. Enhanced AABW leads to a positive feedback between SST increase and atmospheric $\mathrm{CO}_{2}$ rise through the solubility effect (Fig. 5 green and red), thus explaining a major part of the early deglacial warming at mid- and high southern latitudes.

Processes driving atmospheric $\mathrm{CO}_{2}, \delta^{13} \mathrm{CO}_{2}$ and $\Delta^{14} \mathrm{C}$ changes. To investigate the mechanisms driving atmospheric $\mathrm{CO}_{2}$ increase and $\delta^{13} \mathrm{CO}_{2}$ decrease during $\mathrm{HS} 1$, three additional transient simulations (LH1, LH1-SO, LH1-SHW) are performed with LOVECLIM (Fig. 3, Methods). Similar to the simulation presented in Fig. 1 (LH1-SO-SHW, red), the experiments start from a LGM state featuring meltwater input in the Southern Ocean and weaker SH westerlies, and include a meltwater input in the North Atlantic during HS1 (Fig. 3a-c).

For LH1, Southern Ocean meltwater input and weaker SH westerlies are kept at the LGM level thus maintaining weak AAIW and AABW formation (Fig. 3, magenta). Enhanced NPIW decreases the carbon content at intermediate depths in the North Pacific ( 700-2500 m depth), but NADW cessation leads to carbon accumulation in the Atlantic Ocean, mostly as respired carbon (Supplementary Fig. 3) at intermediate depths in the North Atlantic (Fig. 2, Supplementary Fig. 5). As a result, there is little change in atmospheric $\mathrm{CO}_{2}, \delta^{13} \mathrm{CO}_{2}$ or $\Delta^{14} \mathrm{C}$ (Fig. 3h, i, Supplementary Fig. 6 and Table 1), as ventilation of North Pacific intermediate waters is compensated by reduced Atlantic ventilation.

In LH1-SO, the meltwater input in the Southern Ocean is stopped, resulting in stronger $\mathrm{AABW}$, but $\mathrm{SH}$ westerlies and AAIW stay weak (Fig. 3d, e, green). Enhanced AABW steepens Southern Ocean isopycnals (Supplementary Fig. 5) and strengthens deep ocean ventilation, thus decreasing the ocean carbon content below $2000 \mathrm{~m}$ depth, particularly in the Pacific Ocean (Supplementary Table 1$)^{40}$. This leads to a gradual $15 \mathrm{ppm}$ atmospheric $\mathrm{CO}_{2}$ increase through Southern Ocean $\mathrm{CO}_{2}$ outgassing (Supplementary Fig. 7). In addition, the ventilation of ${ }^{13} \mathrm{C}$ and ${ }^{14} \mathrm{C}$ depleted deep ocean causes slow atmospheric $\delta^{13} \mathrm{C}$ and $\Delta^{14} \mathrm{C}$ decreases of 0.016 and $130 \%$, respectively ${ }^{21}$ (Fig. $3 \mathrm{~h}$ and Supplementary Fig. 6). However, the simulated rates of change of $\mathrm{CO}_{2}$ and $\delta^{13} \mathrm{CO}_{2}$ are smaller than recorded in Antarctic ice cores and constant throughout HS1, despite a step-wise forcing. As ventilating the deep ocean is a multi-centennial process, even relatively rapid $\mathrm{AABW}$ changes cannot reproduce the fast atmospheric $\mathrm{CO}_{2}$ increase at $16.2 \mathrm{ka}$.

Finally, when the $\mathrm{SH}$ westerly windstress is intensified but the Southern Ocean meltwater input is kept at LGM level (LH1-SHW, Fig. 3b-e, blue), both AAIW and AABW strengthen and the isopycnal slopes steepen in the Southern Ocean with deep and intermediate waters outcropping south of $50^{\circ} \mathrm{S}$ (Supplementary Fig. 5$)^{41}$. This results in very abrupt $\mathrm{CO}_{2}$ outgassing in the Southern Ocean (Supplementary Fig. 7), and leads to a $8 \mathrm{ppm}$ atmospheric $\mathrm{CO}_{2}$ rise and $0.2 \% \delta^{13} \mathrm{CO}_{2}$ decline within $\sim 100$ years at $16.2 \mathrm{ka}$. 


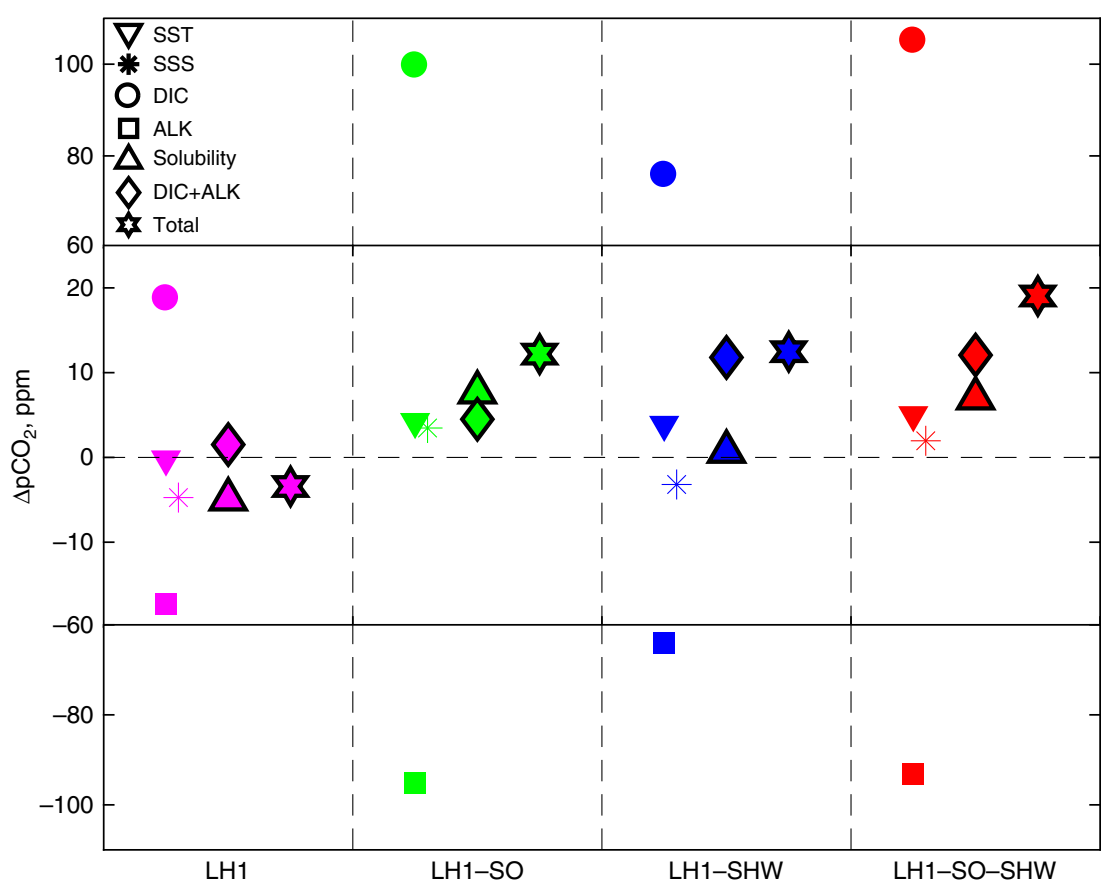

Fig. 5 Attribution of $p \mathrm{CO}_{2}$ changes. Deconvolution of $\triangle \mathrm{pCO}_{2}$ into (from left to right in each column) its SST (downward-pointing triangles), SSS (sixpointed asterisks), DIC (circles) and ALK (squares); solubility (SST + SSS, upward-pointing triangles) and combined DIC and ALK components (diamonds Methods); and total $p \mathrm{CO}_{2}$ change (six-pointed stars), for all transient experiments (LH1: weak AABW, magenta; LH1-SO: strong AABW through buoyancy forcing, green; $\mathrm{LH} 1-\mathrm{SHW}$ : strong AABW through SH westerlies, blue; and LH1-SO-SHW strong AABW through buoyancy forcing and wind, red)

A further weakening of the oceanic circulation from the LGM into HS1 as simulated in experiment LH1 only leads to small changes in the carbon reservoirs (Supplementary Table 1), with a slight global increase in the remineralized $\mathrm{PO}_{4}$ content, and a $2 \%$ decrease in the preformed $\mathrm{PO}_{4}$ content (Supplementary Fig. 3). In contrast, enhanced Southern Ocean ventilation leads to a carbon loss in the Pacific Ocean associated with a global decrease in remineralized $\mathrm{PO}_{4}$ and a $\sim 6 \%$ increase in preformed $\mathrm{PO}_{4}$, thus implying a reduced efficiency of the biological pump in all experiments with enhanced AABW formation (LH1-SO, LH1-SHW and LH1-SO-SHW).

However, the processes leading to the atmospheric $\mathrm{CO}_{2}$ increase also depend on the nature of the forcing: buoyancy (LH1-SO) or dynamic (LH1-SHW) forcing. Enhanced AABW via reduced surface freshwater flux leads to a global SST increase coupled to an increase in surface salinity, which induces a $8 \mathrm{ppm}$ $\mathrm{CO}_{2}$ rise through the solubility effect (Fig. 5, green triangle). In contrast, no notable $\mathrm{CO}_{2}$ increase occurs through the solubility effect in the wind only forcing case (Fig. 5, blue triangle). While stronger deep ocean convection triggered by changes in the buoyancy forcing increases the southward baroclinic flow and thus the oceanic meridional heat transport to high southern latitudes ${ }^{39}$, the SST response to changes in windstress is more complex. Stronger windstress over the Southern Ocean increases the Ekman transport and enhances the oceanic heat loss to the atmosphere, thus triggering an initial cooling in some areas of the Southern Ocean. However, after $\sim 20$ years, the eddy-driven poleward flow and enhanced upwelling of relatively warm Circumpolar Deep Water reverse the cooling trend into a warming trend ${ }^{42}$. In addition, an intensification of $\mathrm{SH}$ westerlies leads to an increase in the ventilation of low salinity AAIW, resulting in a global sea surface salinity (SSS) decrease.

The $\mathrm{CO}_{2}$ rise in the wind forced simulation is due to an imbalance between Dissolved Inorganic Carbon (DIC) and alkalinity (ALK) increase (Fig. 5, blue diamond). As seen in Fig. 2, stronger AABW and enhanced upwelling in the Southern
Ocean lead to a DIC transfer from deep and intermediate depths of the Pacific and Southern Oceans up to the surface of the Southern Ocean. While an increase in surface DIC leads to an atmospheric $\mathrm{CO}_{2}$ rise, an increase in surface ALK has an opposite effect. DIC and ALK thus tend to compensate each other as their oceanic distributions are similar (Supplementary Fig. 9) and their fractional impacts on $\mathrm{CO}_{2}$ are of similar magnitude but opposite (Methods). When AABW is enhanced through reduced buoyancy forcing, this imbalance leads to a $5 \mathrm{ppm} \mathrm{CO}_{2}$ increase, while it causes the $12 \mathrm{ppm} \mathrm{CO}$ increase in the wind forcing case (Fig. 5, blue and green diamonds). This difference is mainly due to enhanced formation of AAIW in the simulation with stronger $\mathrm{SH}$ westerlies (Fig. 3e). Stronger AAIW formation entrains intermediate depth waters, characterised by low alkalinity, to the surface. In addition, this process acts on a faster timescale than deep ocean ventilation through enhanced AABW.

Both $\delta^{13} \mathrm{CO}_{2}$ and $\Delta^{14} \mathrm{C}$ decrease are abrupt and of higher amplitude in the wind forcing experiment because of ventilation of intermediate waters and enhanced air-sea gas exchange, which is particularly important for carbon isotopes. When multimillennial deep ocean ventilation and solubility decrease are combined with decadal scale changes in intermediate waters (Fig. 5 red, LH1-SO-SHW), the atmospheric $\mathrm{CO}_{2}$ increase is in close agreement with ice core records (Fig. 1d).

The atmospheric $\Delta^{14} \mathrm{C}$ changes shown in Fig. If and S6 were obtained by keeping the atmospheric ${ }^{14} \mathrm{C}$ production rate constant at LGM levels (Methods). Our results thus suggest that most, if not all, of the atmospheric $\Delta^{14} \mathrm{C}$ changes can be attributed to changes in ocean circulation and air-sea gas exchange with a smaller contribution from a varying atmospheric ${ }^{14} \mathrm{C}$ production rate (Supplementary Fig. 4). The relatively large changes in atmospheric $\Delta^{14} \mathrm{C}$ simulated here are in line with a deglacial experiment performed with CLIMBER- $2^{43}$ showing the dominant role of reduced Southern Ocean stratification in decreasing atmospheric $\Delta^{14} \mathrm{C}$ across HS1. However, the simulated atmospheric $\Delta^{14} \mathrm{C}$ decrease is larger than the one simulated by 
global carbon cycle box models ${ }^{44,45}$, probably because of the large oceanic $\Delta^{14} \mathrm{C}$ gradient present in the initial LGM state, itself resulting from the weak LGM oceanic circulation.

While the simulated changes in atmospheric $\delta^{13} \mathrm{CO}_{2}$ and $\Delta^{14} \mathrm{C}$ are in very good agreement with paleo-records, the $\mathrm{pCO}_{2}$ increase is slightly underestimated over the last 1000 years of HS1. This could be due to an overestimation of the surface alkalinity increase in these simulations (Fig. 5 squares). It is important to note that the global ocean alkalinity inventory was kept constant during these transient simulations. However, a rising sea-level and an increase in deep ocean carbonate ion saturation during $\mathrm{HS}^{29}$ could have enhanced carbonate sedimentation, thus leading to a reduced global alkalinity content. Assuming a total glacial-interglacial alkalinity change of $96 \mu \mathrm{mol} \mathrm{L}^{-1}$ (Methods), an ocean alkalinity decrease of $6 \mu \mathrm{mol} \mathrm{L}^{-1}$ per 1000 years would induce a steady atmospheric $\mathrm{CO}_{2}$ rise of $\sim 5$ ppm per 1000 years (orange line in Fig. 1d).

Recent studies ${ }^{19,28}$ raised the possibility that the abrupt $\mathrm{CO}_{2}$ increase occurring at $16.2 \mathrm{ka}$ could be due to a Northern Hemisphere terrestrial carbon release resulting from a southward shift of the ITCZ. Our model-data comparison shows instead that an increase in Southern Ocean ventilation during HS1 cause an abrupt atmospheric $\mathrm{CO}_{2}$ rise and $\delta^{13} \mathrm{CO}_{2}$ decline in agreement with ice core and marine sediment records. In addition, our simulated terrestrial carbon content increases during this period due to a higher $\mathrm{CO}_{2}$ content and warmer conditions (Fig. $3 \mathrm{~g}$ ). However, given the short duration of the $16.2 \mathrm{ka}$ event and the relative low resolution of marine sediment records, a terrestrial carbon release cannot be ruled out (Supplementary Fig. 8).

Our simulations suggest that enhanced ventilation of AABW and AAIW played a crucial role in driving the atmospheric $\mathrm{CO}_{2}$ increase during HS1. Stronger AABW transfers carbon from the deep ocean to the atmosphere, and concurrently leads to a warming south of $30^{\circ} \mathrm{S}$ on a millennial timescale. In contrast, increased AAIW formation caused by $\mathrm{SH}$ westerlies leads to a multi-decadal $\mathrm{CO}_{2}$ rise.

Rapid ocean carbon release in a global eddy-permitting model. The strength of SH westerly winds exerts a strong control on the slope of Southern Ocean isopycnals and on the strength of the oceanic circulation. Mesoscale eddies are ubiquitous in the Southern Ocean and have a tendency to compensate for many of the wind-driven circulation changes that appear in non-eddying models ${ }^{46}$. To test whether the Southern Ocean $\mathrm{CO}_{2}$ outgassing response to a strengthening of $\mathrm{SH}$ westerlies shown above is a robust feature, we perform an experiment under fixed modernday forcing with a global high-resolution ocean sea-ice carbon cycle model that resolves most of the ocean mesoscale energy (Methods). The model is perturbed with a poleward intensifying Southern Ocean wind scenario based on observed and projected 21st century wind trends (Supplementary Fig. 10). The model's response is dominated by a large polynya in the Weddell Sea, that is similar in scale to an observed 1970's Weddell Sea polynya ${ }^{47}$ and lasts for $\sim 6$ years (Supplementary Fig. 10). The polynya intensifies deep convection in the Weddell Sea, thus leading to a strengthening of $\mathrm{AABW}$ from 19 to $30 \mathrm{~Sv}$ and a $\mathrm{CO}_{2}$ outgassing in the Southern Ocean (Fig. 6a, b). Open-ocean convection was likely the dominant source of AABW formation during glacial periods because grounded ice covered most of the Weddell and Ross Seas ${ }^{48}$, where AABW is primarily formed today. Enhanced ventilation of intermediate and bottom waters, and associated increased upwelling of Circumpolar Deep Water lead to a total ocean carbon loss of $42 \mathrm{GtC}$ over 50 years, corresponding to an upper estimate of $\sim 20 \mathrm{ppm}$ atmospheric $\mathrm{CO}_{2}$ increase. Ventilation of Southern Ocean is rapid and leads to large
( -60 $\left.\mu \mathrm{mol} \mathrm{L}^{-1}\right)$ DIC anomalies at intermediate depths (Fig. 6c). At $4300 \mathrm{~m}$ depth, negative DIC anomalies spread from the Southern Ocean towards the western Pacific and Atlantic basins, reaching about $20^{\circ} \mathrm{N}$ after 50 years (Fig. 6d). Enhanced chlorofluorocarbon content in bottom and intermediate waters further confirms enhanced AABW and AAIW ventilation (Supplementary Fig. 11).

Similar to the coarse resolution experiment, most of the $\mathrm{CO}_{2}$ flux is caused by a surface-water DIC increase, due to enhanced Ekman pumping of DIC-rich waters, with a strong compensation effect coming from the associated alkalinity increase (Supplementary Fig. 12a, b). However, warming of surface waters south of Australia and in the South Atlantic (Supplementary Fig. 12c), due to a poleward shift of the subtropical front, also significantly contributes to the $\mathrm{CO}_{2}$ flux. In agreement with the simulations performed with LOVECLIM, global export production increases due to enhanced nutrient upwelling. Even though this simulation was performed under fixed modern-day forcing and the carbon cycle response to a latitudinal shift of the $\mathrm{SH}$ westerlies could depend on their initial position ${ }^{24}$, this high-resolution simulation supports the significant role played by intensified $\mathrm{SH}$ westerlies in driving abrupt Southern Ocean $\mathrm{CO}_{2}$ outgassing.

\section{Discussion}

Reduced NADW formation during $\mathrm{HS}^{13}$ weakens the meridional heat transport to the North Atlantic and induces a Southern Ocean warming, but our simulations suggest that the magnitude of this direct heat redistribution is small. In addition, reduced North Atlantic ventilation increases the carbon content in the Atlantic Ocean (Supplementary Table 1). Through oceanic and atmospheric teleconnections, NADW cessation enhances the formation of NPIW, thus ventilating the intermediate North Pacific. However, the decrease in North Pacific oceanic carbon content is compensated by the carbon increase in the North Atlantic, with negligible net effect on atmospheric $\mathrm{CO}_{2}$ (Fig. 3i, Supplementary Fig. 5). Other mechanisms impacting SH climate and/or carbon cycle must have therefore been at play.

Modelling studies ${ }^{34,35}$ have shown that the North Atlantic cooling can strengthen and shift the $\mathrm{SH}$ westerlies poleward via a southward shift of the ITCZ (Fig. 2). During the first phase of weak NADW transport at $\sim 17.2 \mathrm{ka}^{13}$, an intensification of the SH westerlies and associated enhanced Southern Ocean deep convection could have led to a rise in atmospheric $\mathrm{CO}_{2}$ concentration and initiated the deglaciation at high southern latitudes. Our simulations show that the resulting enhanced transport of AABW leads to a transfer of carbon from the deep Pacific to the surface of the Southern Ocean, thus inducing a millenial-scale atmospheric $\mathrm{CO}_{2}$ increase. In addition, enhanced AAIW formation and the associated increased upwelling of Circumpolar Deep Water, lead to a multi-decadal $p \mathrm{CO}_{2}$ increase. Both stronger $\mathrm{SH}$ westerlies and buoyancy loss near the Antarctic continent act to steepen Southern Ocean isopycnals, thus increasing the southward baroclinic flow. This results in a stronger southward meridional heat transport ${ }^{39}$, decreasing Southern Ocean sea-ice concentration and further warming the mid- to high southern latitudes. Our simulations thus suggest that through its impact on both atmospheric $\mathrm{CO}_{2}$ and temperature, enhanced Southern Ocean ventilation played a significant role during the last deglaciation.

Changes in $\mathrm{SH}$ westerlies, Southern Ocean circulation and the resulting impact on the hydrological cycle and terrestrial biosphere could have reduced the aeolian iron input into the Southern Ocean, thus potentially contributing to the atmospheric $\mathrm{CO}_{2}$ rise during $\mathrm{HS}^{5}$. However, changes in iron fertilisation alone cannot explain the observed variations in atmospheric 
a $\mathrm{CO}_{2}$ flux out of the ocean (mol/ $\mathrm{m}^{2} /$ years)

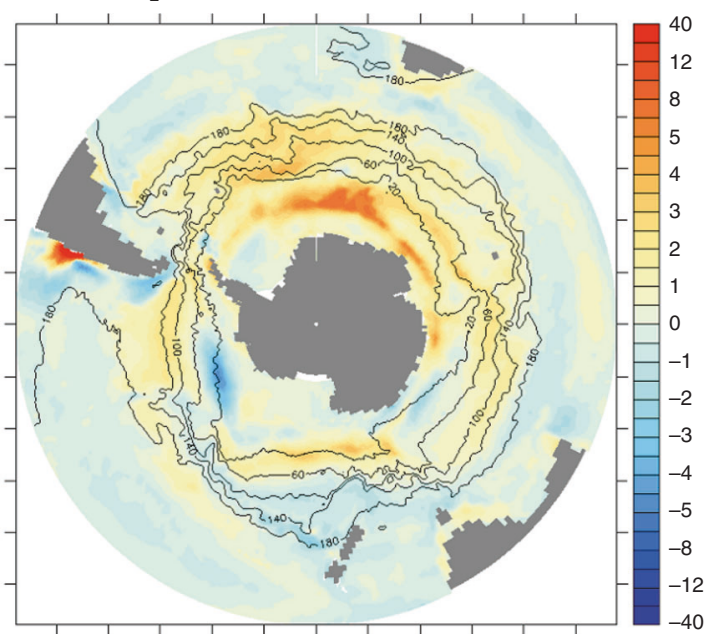

b

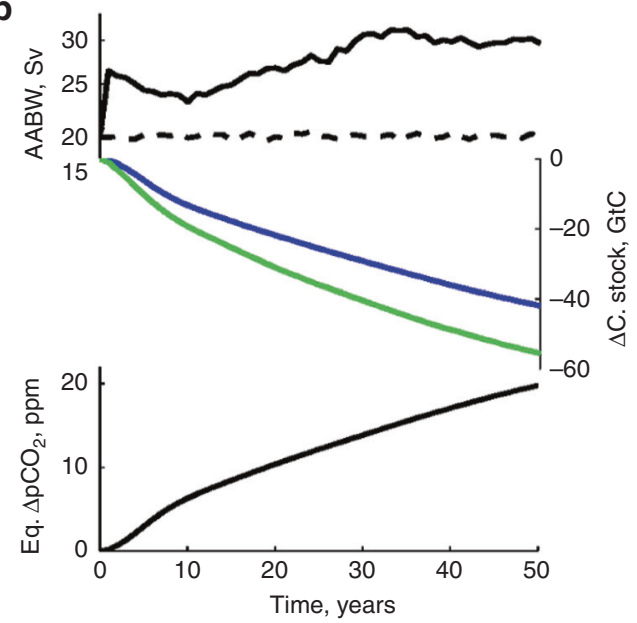

C

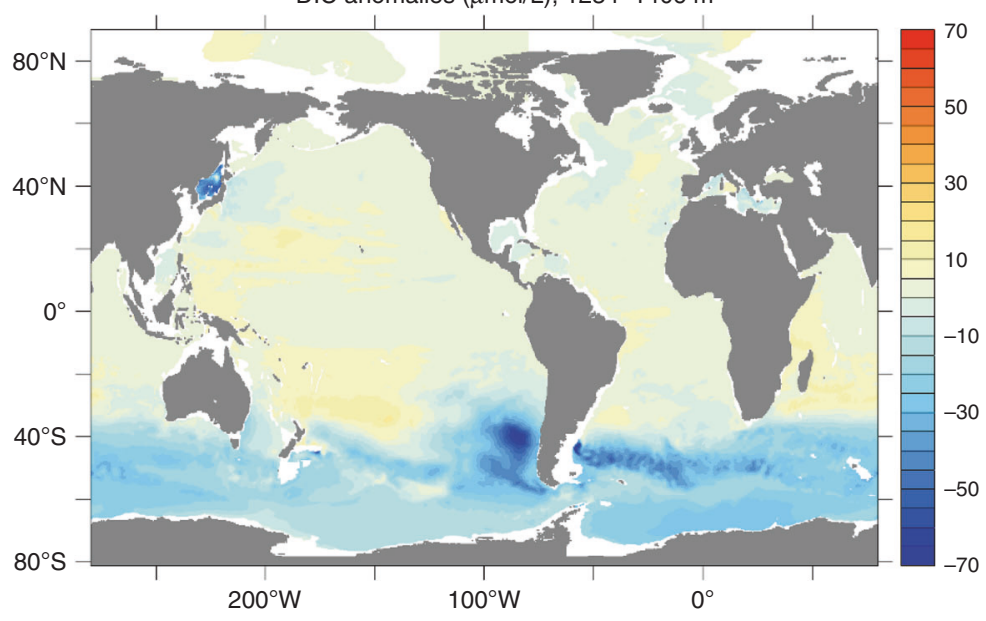

d

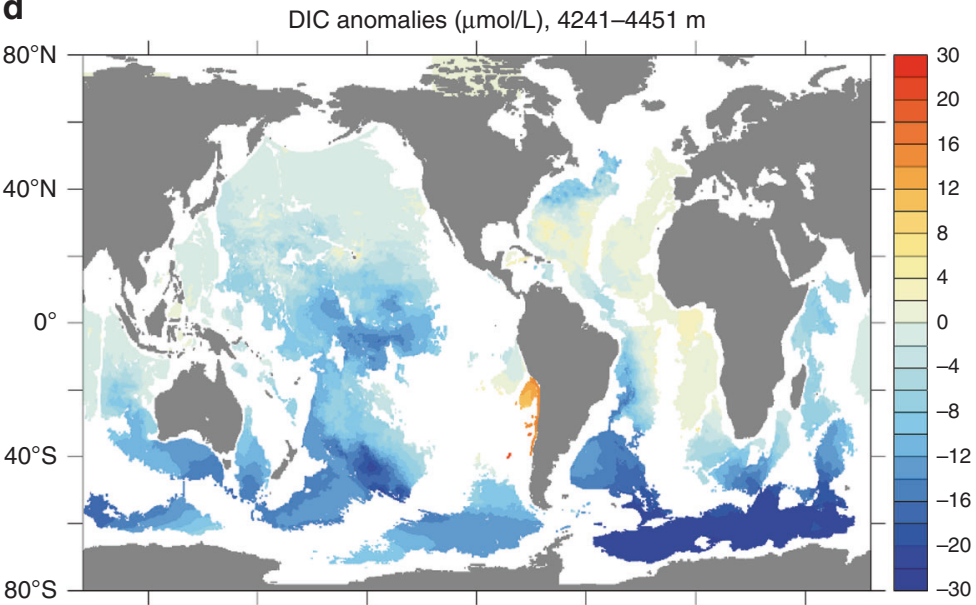

Fig. 6 Oceanic carbon response to poleward intensified $\mathrm{SH}$ westerlies as simulated by a global eddy-permitting model. a $\Delta \mathrm{CO}_{2}$ flux out of the ocean (shading, mol m-2 $\mathrm{yr}^{-1}$ ) with Antarctic Circumpolar Current stream lines (Sv) overlaid for the poleward intensified SH westerlies case. $\mathbf{b}$ Timeseries of maximum AABW transport in the perturbed (solid) and control (dashed) experiments, total (blue) and south of $36^{\circ} \mathrm{S}$ (green) ocean carbon change and $\mathrm{pCO}_{2}$ equivalent ( $\Delta \mathrm{C}_{\mathrm{od}}$ 2.12); DIC anomalies ( $\mu \mathrm{mol} \mathrm{L}^{-1}$ ) at water depths $\mathbf{c} 1234-1406 \mathrm{~m}$ and $\mathbf{d} 4241-4451 \mathrm{~m}$. Anomalies are at year 50 compared to year 50 of the control run

$\Delta^{14} \mathrm{C}$, ocean ventilation and high southern latitude warming. We therefore suggest that changes in iron fertilisation mostly respond to changes in sea-level and Southern Ocean ventilation, possibly providing a positive feedback. In addition, while marine export production decreased north of the polar front ${ }^{5}$, marine sediment cores south of the polar front display an increase in opal flux ${ }^{9}$, thus indicating a limited geographic extent of iron fertilisation changes.

Sediment records from the Iberian margin have shown that $\sim 16.2$ ka probably corresponds to the beginning of Heinrich event 1 stricto sensu ${ }^{37}$, and to another phase of NADW weakening ${ }^{36}$. North Pacific records suggest that after a period of strong NPIW formation during the first phase of HS1, NPIW weakened significantly at $\sim 16.2 \mathrm{ka}^{33,49}$. In addition, Chinese speleothems record a shift to significantly drier conditions at $\sim 16.1 \mathrm{ka}^{50}$ (Supplementary Fig. 2). Both NADW and NPIW weakening at $\sim 16.2 \mathrm{ka}$ would cool the Northern Hemisphere, thus shifting the ITCZ southward, including in the Pacific sector ${ }^{51}$ (Supplementary Fig. 1). This would further strengthen/shift the SH westerlies, enhance Southern Ocean deep convection and lead to the abrupt atmospheric $\mathrm{CO}_{2}$ increase and $\delta^{13} \mathrm{CO}_{2}$ decrease at $\sim 16.2 \mathrm{ka}$. A rapid $\mathrm{CO}_{2}$ outgassing in the Southern Ocean due to intensified $\mathrm{SH}$ westerlies is confirmed by a simulation performed with a global ocean eddy-permitting model (Fig. 6).

Taking smoothing and dating uncertainties $(\sim 1 \mathrm{kyr})$ into account, the above sequence of events is in agreement with radiocarbon records, which suggest increased ventilation of the deep South Atlantic ${ }^{6}$ and Pacific ${ }^{52}$ and enhanced mixing between deep and intermediate waters at high southern latitudes ${ }^{38,53}$ during HS1 (Figs. 1h, i and 4c, d). In addition, enhanced ventilation of deep and intermediate waters is consistent with positive benthic $\delta^{13} \mathrm{C}$ anomalies across HS1 south of $30^{\circ} \mathrm{S}$ and below 1000 $\mathrm{m}$ depth $^{38,54,55}$ (Figs. $1 \mathrm{~g}$ and $4 \mathrm{a}, \mathrm{b}$ ) as well as high opal production in the Antarctic zone 9 .

Our study highlights the crucial role of $\mathrm{SH}$ westerlies in driving abrupt atmospheric $\mathrm{CO}_{2}$ rise and associated global climate changes. Given the projected poleward intensification of $\mathrm{SH}$ westerlies over the 21st Century, and the fact that the Southern Ocean has absorbed $\sim 10 \%$ of anthropogenic $\mathrm{CO}_{2}$ emissions ${ }^{56,57}$, our results suggest a future reduction in $\mathrm{CO}_{2}$ sequestration in the Southern Ocean, with significant impacts on future atmospheric $\mathrm{CO}_{2}$ and climate change. 


\section{Methods}

Carbon isotopes-enabled earth system model and LGM state. Transient experiments were performed with the carbon isotope-enabled $\left({ }^{13} \mathrm{C}\right.$ and $\left.{ }^{14} \mathrm{C}\right)$ Earth system model LOVECLIM ${ }^{58}$. This coupled model consists of a free-surface primitive equation ocean model $\left(3^{\circ} \times 3^{\circ}, 20\right.$ vertical levels $)$, a dynamic-thermodynamic sea ice model, an atmospheric model based on quasigeostrophic equations of motion (T21, three vertical levels), a land surface scheme, a dynamic global vegetation model ${ }^{59}$ and a marine carbon cycle model ${ }^{21,60}$.

The initial LGM state was selected amongst 28 LGM experiments based on its representation of oceanic $\delta^{13} \mathrm{C}$ and ventilation age distributions ${ }^{31}$. It was obtained by equilibrating LOVECLIM under $35 \mathrm{ka}$ B.P. boundary conditions, namely appropriate orbital parameters ${ }^{61}$, Northern Hemisphere ice-sheet extent, topography and albedo ${ }^{62}$, an atmospheric $\mathrm{CO}_{2}$ content of $190 \mathrm{ppm}$, a $\delta^{13} \mathrm{CO}_{2}$ of $-6.46 \%$ and $\Delta^{14} \mathrm{C}$ of $393 \%$. After a 10,000 years long equilibration phase, the model was run transiently until $20 \mathrm{ka}$ with prognostic atmospheric $\mathrm{CO}_{2}, \delta^{13} \mathrm{CO}_{2}$ and $\Delta^{14} \mathrm{C}$. During the equilibration phase, an atmospheric ${ }^{14} \mathrm{C}$ production rate of 2.05 atoms $\mathrm{cm}^{-2} \mathrm{~s}^{-1}$ was diagnosed and then subsequently applied for all transient simulations, except for the deglacial simulations presented in Supplementary Fig. 4 in which the ${ }^{14} \mathrm{C}$ production rate is varied according to Hain et al. ${ }^{44}$. This rate is higher than Holocene and present-day ${ }^{14} \mathrm{C}$ production rate estimates ${ }^{63,64}$ of 1.64 and 1.88 atoms $\mathrm{cm}^{-2} \mathrm{~s}^{-1}$, consistent with a relatively high $\mathrm{LGM}^{20} \Delta^{14} \mathrm{C}$.

The LGM state features weak (11.2 Sv) and shallow $(\sim 2500 \mathrm{~m})$ NADW and very weak AABW (5.1 Sv) obtained through $20 \%$ weaker SH westerlies and a $0.1 \mathrm{~Sv}$ meltwater input into the Southern Ocean ${ }^{31}$.

Transient experiments of HS1. A suite of transient experiments is performed starting from this LGM state by forcing the model with time-varying changes in orbital parameters $^{61}$ and Northern Hemispheric ice-sheet extent, topography and albedo $^{62}$. In addition, meltwater is added to the northern North Atlantic (grey line, Fig. 3a) to obtain a nearly collapsed NADW. To explore the impact of changes in AABW on the global carbon cycle and climate, additional experiments are performed whereby AABW is enhanced by decreasing the buoyancy forcing (LH1-SO, LH1-SO-SHW) in the Southern Ocean and/or enhancing the simulated southern hemispheric westerly windstress (LH1-SHW, LH1-SO-SHW; Fig. 3b, c). The magnitudes of these changes in windstress are within estimates of probable windstress changes. Indeed some PMIP3 models display 10-20\% weaker SH westerly winds at the LGM compared to pre-industrial times ${ }^{65}$ and SH westerlies have increased by $\sim 8 \%$ from 1990 to 2010 (equivalent to a $\sim 15 \%$ increase in windstress $)^{66}$ and are forecast to keep on strengthening by $\sim 15 \%$ over the coming century ${ }^{67}$

In all transient experiments presented here, the atmospheric ${ }^{14} \mathrm{C}$ production rate is kept constant and so is the total ocean alkalinity content except for the simulation shown by the orange line in Fig. 1d, where the total ocean alkalinity was decreased at a rate of $6 \mu \mathrm{mol} \mathrm{L}-1$ per 1000 years starting at $16.2 \mathrm{ka}$. The magnitude of that decrease is equivalent to a linear global alkalinity decrease of $96 \mu \mathrm{mol} \mathrm{L}^{-1}$ over a time interval of 16,000 years. This corresponds to a first order approximation based on total alkalinity conservation and on changes in ocean volume ( $V$, linked to sea-level changes): $\overline{\left[\mathrm{ALK}_{\mathrm{PI}}\right]} * V_{\mathrm{PI}}=\overline{\left[\mathrm{ALK}_{\mathrm{LGM}}\right]} * V_{\mathrm{LGM}}$.

The timeseries of AABW and AAIW transport refer to the maximum stream function of the zonally integrated meridional transport south of $60^{\circ} \mathrm{S}$ for AABW and at $1225 \mathrm{~m}$ between 30 and $60^{\circ} \mathrm{S}$ for AAIW.

Decomposition of $\mathbf{p} \mathrm{CO}_{\mathbf{2}}$ changes. Changes in surface water $p \mathrm{CO}_{2}$, which exert a dominant control on atmospheric $\mathrm{CO}_{2}$, arise due to changes in DIC, ALK and solubility (SSS and SST) ${ }^{68} \cdot \mathrm{pCO}_{2}$ changes can thus be decomposed as follows (Fig. 5):

$$
\Delta p \mathrm{CO}_{2}=\Delta p \mathrm{CO}_{2 \mathrm{DIC}}+\Delta p \mathrm{CO}_{2 \mathrm{ALK}}+\Delta p \mathrm{CO}_{2 \mathrm{SST}}+\Delta p \mathrm{CO}_{2 \mathrm{SSS}}
$$

For DIC, ALK and SSS, $\Delta p \mathrm{CO}_{2}$ can be expressed as

$$
\Delta p \mathrm{CO}_{2 X}=\Delta X * \gamma_{X} * p \mathrm{CO}_{2 \operatorname{Ref}} / \bar{X}
$$

where $p \mathrm{CO}_{2 \mathrm{Ref}}$ is the $p \mathrm{CO}_{2}$ value at $19 \mathrm{ka} ; \bar{X}$ represents the mean surface DIC, ALK or salinity value and $\gamma_{\mathrm{DIC}}, \gamma_{\mathrm{ALK}}, \gamma_{\mathrm{SSS}}$ are Revelle factors equal to $10,-9.4$ and 1 , respectively 68

The temperature contribution is derived from

$$
\Delta p \mathrm{CO}_{2 \mathrm{SST}}=e^{\left(\Delta \mathrm{SST} * \gamma_{\mathrm{SST}}\right)} * p \mathrm{CO}_{2 \mathrm{Ref}}-p \mathrm{CO}_{2 \mathrm{Ref}}
$$

where $\gamma_{\mathrm{SST}}$ is equal to $0.0423\left({ }^{68}\right)$.

Eddy-permitting global ocean sea-ice carbon cycle model. Experiments are conducted with the eddy-permitting global ocean, sea-ice model MOM5, which is based on the Geophysical Fluid Dynamics Laboratory CM2.4 and CM2.5 coupled climate models ${ }^{69,70}$. The model has a $1 / 4^{\circ}$ Mercator horizontal resolution with $\sim 11$ $\mathrm{km}$ grid spacing at $65^{\circ} \mathrm{S}$. The MOM5 ocean model has 50 vertical levels and is coupled to the Sea Ice Simulator dynamic/thermodynamic sea-ice model. The atmospheric forcing is derived from version 2 of the Coordinated Ocean-ice
Reference Experiments Normal Year Forcing (CORE-NYF) reanalysis data ${ }^{71,72}$. CORE-NYF provides a modern-day climatological mean atmospheric state at 6-h intervals for 1 year and includes synoptic variability.

The model is coupled to the Whole Ocean Model with Biogeochemistry and Trophic-dynamics (WOMBAT) model, a Nutrient-Phytoplankton-ZooplanktonDetritus (NPZD) model ${ }^{73,74}$. WOMBAT includes DIC, alkalinity, oxygen, phosphate and iron, which are linked to the phosphate uptake and remineralisation through a constant Redfield ratio. Phytoplankton growth is limited by light, phosphate and iron, with the minimum of these three terms limiting growth. The biogeochemical parameters are slightly modified from the values used in the ACCESS-ESM simulations ${ }^{75,76}$. Two important changes needed for the highresolution simulations were to increase detritus sinking rate to $20 \mathrm{~m} \mathrm{~d}^{-1}$ and the background iron concentration was set to $0.3 \mu \mathrm{mol} \mathrm{Fe} \mathrm{m}^{-3}$ to reduce nutrient trapping and improve export production in the tropical East Pacific. The formation of calcium carbonate is a constant fraction of organic carbon production. The air-sea exchange of carbon dioxide is a function of wind speed ${ }^{77}$ and sea ice concentration. Initial conditions for the biophysical fields are derived from an observation-based climatology ${ }^{78}$.

The model was initialised with modern-day temperature and salinity distributions and equilibrated for 180 years of Normal Year Forcing (CORE-NYF). A control run and a wind perturbation experiment were then run for 50 years. The wind perturbation experiment includes a poleward intensifying wind forcing, namely a $4^{\circ}$ southward shift and $15 \%$ increase in $10 \mathrm{~m}$ wind speeds between $30^{\circ} \mathrm{S}$ and $65^{\circ} \mathrm{S}$ (Supplementary Fig. 10). This wind forcing is based on projected SH wind changes in CMIP5 business as usual scenarios ${ }^{67}$. The model setup and experimental design are similar to the one employed in a previous study ${ }^{79}$, except that previous simulations did not use any neutral physics ocean parameterisations. In the simulations presented here, neutral physics parameterisations are used, based on options from the ACCESS Ocean Model ${ }^{80}$, with Redi diffusivity $\left(600 \mathrm{~m}^{2} \mathrm{~s}^{-1}\right)$ and Gent McWilliams skew diffusion $\left(600 \mathrm{~m}^{2} \mathrm{~s}^{-1}\right)$. These neutral physics options improved the simulated AABW transport and the distribution of ocean biogeochemical tracers relative to observations, for instance, the oxygen in the Southern Ocean and alkalinity of bottom waters penetrating into ocean basins (Supplementary Fig. 9).

Data availability. Results of the modelling experiments are available at https://doi. org/10.4225/41/5af39aae7960f and under T1c13 at http://climate-cms.unsw. wikispaces.net/ARCCSS+published+datasets.

Received: 29 October 2017 Accepted: 25 May 2018

Published online: 27 June 2018

\section{References}

1. Lüthi, D. et al. High-resolution carbon dioxide concentration record 650,000-800,000 years before present. Nature 453, 379-382 (2008).

2. Sigman, D., Hain, M. \& Haug, G. The polar ocean and glacial cycles in atmospheric $\mathrm{CO}_{2}$ concentration. Nature 466, 47-55 (2010).

3. Bopp, L., Kohfeld, K., Quéré, C. L. \& Aumont, O. Dust impact on marine biota and atmospheric $\mathrm{CO}_{2}$ during glacial periods. Paleoceanography 18, 1046 (2003).

4. Tagliabue, A. et al. Quantifying the roles of ocean circulation and biogeochemistry in governing ocean carbon-13 and atmospheric carbon dioxide at the Last Glacial Maximum. Clim. Past. 5, 695-706 (2009).

5. Martínez-García, A. et al. Iron fertilization of the subantarctic ocean during the last ice age. Science 343, 1347-1350 (2014).

6. Skinner, L., Fallon, S., Waelbroeck, C., Michel, E. \& Barker, S. Ventilation of the deep Southern Ocean and deglacial $\mathrm{CO}_{2}$ rise. Science 328, 1147-1151 (2010).

7. Marcott, S. et al. Centennial-scale changes in the global carbon cycle during the last deglaciation. Nature 514 (7524), 616-619 (2014).

8. Toggweiler, J., Russell, J. \& Carson, S. Midlatitude westerlies, atmospheric $\mathrm{CO}_{2}$, and climate change during ice ages. Paleoceanography 21, PA2005 (2006).

9. Anderson, R. F. et al. Wind-driven upwelling in the Southern Ocean and the deglacial rise in atmospheric $\mathrm{CO}_{2}$. Science 323, 1443-1448 (2009).

10. Tschumi, T., Joos, F., Gehlen, M. \& Heinze, C. Deep ocean ventilation, carbon isotopes, marine sedimentation and the deglacial $\mathrm{CO}_{2}$ rise. Clim. Past. 7, 771-800 (2011).

11. Lauderdale, J. M., Garabato, A. C. N., Oliver, K. I. C., Follows, M. J. \& Williams, R. G. Wind-driven changes in Southern Ocean residual circulation, ocean carbon reservoirs and atmospheric $\mathrm{CO}_{2}$. Clim. Dyn. 41, 2145-2164 (2013).

12. Schmittner, A. \& Lund, D. Early deglacial Atlantic overturning decline and its role in atmospheric $\mathrm{CO}_{2}$ rise inferred from carbon isotopes $\left(\delta^{13} \mathrm{C}\right)$. Clim. Past. 11, 135-152 (2015).

13. McManus, J. F., Francois, R., Gherardi, J. M., Keigwin, L. D. \& Brown-Leger, S. Collapse and rapid resumption of Atlantic meridional circulation linked to deglacial climate changes. Nature 428, 834-837 (2004). 
14. Buizert, C. et al. Greenland temperature response to climate forcing during the last deglaciation. Science 345, 1177-1180 (2014).

15. Martrat, B. et al. Four climate cycles of recurring deep and surface water destabilizations on the Iberian margin. Science 317, 502-507 (2007).

16. Parrenin, F. et al. Synchronous change of atmospheric $\mathrm{CO}_{2}$ and Antarctic temperature during the last deglacial warming. Science 339, 1060-1063 (2013).

17. Barker, S. et al. Interhemispheric Atlantic seesaw response during the last deglaciation. Nature 457, 1097-1102 (2009).

18. Schmitt, J. et al. Carbon isotope constraints on the deglacial $\mathrm{CO}_{2}$ rise from ice cores. Science 136, 711-714 (2012).

19. Bauska, T. et al. Carbon isotopes characterize rapid changes in atmospheric carbon dioxide during the last deglaciation. Proc. Natl Acad. Sci. 113, 3465-3470 (2016).

20. Reimer, P. et al. IntCal13 and Marine13 radiocarbon age calibration curves, 0-50,000 years cal BP. Radiocarbon 55, 1869-1887 (2013).

21. Menviel, L., Mouchet, A., Meissner, K., Joos, F. \& England, M. Impact of oceanic circulation changes on atmospheric $\delta^{13} \mathrm{CO}_{2}$. Glob. Biogeochem. Cycles 29, 1944-1961 (2015).

22. Menviel, L., Joos, F. \& Ritz, S. Modeling atmospheric $\mathrm{CO}_{2}$, stable carbon isotope and marine carbon cycle changes during the last glacial-interglacial cycle. Quat. Sci. Rev. 56, 46-68 (2012).

23. D'Orgeville, M., Sijp, W., England, M. \& Meissner, K. On the control of glacial-interglacial atmospheric $\mathrm{CO}_{2}$ variations by the Southern Hemisphere westerlies. Geophys. Res. Lett. 37, L21703 (2010).

24. Völker, C. \& Köhler, P. Responses of ocean circulation and carbon cycle to changes in the position of the Southern Hemisphere westerlies at Last Glacial Maximum. Paleoceanography 28, 726-739 (2013).

25. Chavaillaz, Y., Codron, F. \& Kageyama, M. Southern westerlies in LGM and future (RCP4.5) climates. Clim. Past. 9, 517-524 (2013).

26. Kohfeld, K. et al. Southern Hemisphere westerly wind changes during the Last Glacial Maximum: paleo-data synthesis. Quat. Sci. Rev. 68, 76-95 (2013).

27. Crichton, K., Bouttes, N., Roche, D., Chappellaz, J. \& Krinner, G. Permafrost carbon as a missing link to explain $\mathrm{CO}_{2}$ changes during the last deglaciation. Nat. Geosci. 9, 683-686 (2016).

28. Rhodes, R. et al. Enhanced tropical methane production in response to iceberg discharge in the North Atlantic. Science 348, 1016-1019 (2015).

29. Yu, J. et al. Loss of carbon from the deep sea since the Last Glacial Maximum. Science 330, 1084-1087 (2010).

30. Peterson, C., Lisiecki, L. \& Stern, J. Deglacial whole-ocean $\delta^{13} \mathrm{C}$ change estimated from 480 benthic foraminiferal records. Paleoceanography 29 549-563 (2014).

31. Menviel, L. et al. Poorly ventilated deep ocean at the Last Glacial Maximum inferred from carbon isotopes: a data-model comparison study. Paleoceanography 32, 2-17 (2017).

32. Okazaki, Y. et al. Deep water formation in the North Pacific during the Last Glacial termination. Science 329, 200-204 (2010).

33. Rae, J. et al. Deep water formation in the North Pacific and deglacial $\mathrm{CO}_{2}$ rise. Paleoceanography 29, 645-667 (2014).

34. Ceppi, P., Hwang, Y.-T., Liu, X., Frierson, D. \& Hartmann, D. The relationship between the ITCZ and the Southern Hemispheric eddy-driven jet. J. Geophys. Res.: Atmospheres 118, 5136-5146 (2013).

35. Lee, S.-Y., Chiang, J. C. H., Matsumoto, K. \& Tokos, K. S. Southern Ocean wind response to North Atlantic cooling and the rise in atmospheric $\mathrm{CO}_{2}$ : modeling perspective and paleoceanographic implications. Paleoceanography 26, PA1214 (2011).

36. Gherardi, J. et al. Glacial-interglacial circulation changes inferred from ${ }^{231} \mathrm{~Pa} /$ ${ }^{230}$ Th sedimentary record in the North Atlantic region. Paleoceanography 24, PA2204 (2009)

37. Hodell, D. et al. Anatomy of Heinrich Layer 1 and its role in the last deglaciation. Paleoceanography 32, 284-303 (2017).

38. Siani, G. et al. Carbon isotope records reveal precise timing of enhanced Southern Ocean upwelling during the last deglaciation. Nat. Commun. 4, 2758 (2013).

39. Menviel, L., Spence, P. \& England, M. Contribution of enhanced Antarctic Bottom Water formation to Antarctic warm events and millennial-scale atmospheric $\mathrm{CO}_{2}$ increase. Earth. Planet. Sci. Lett. 413, 37-50 (2015).

40. Menviel, L., England, M., Meissner, K., Mouchet, A. \& Yu, J. Atlantic-Pacific seesaw and its role in outgassing $\mathrm{CO}_{2}$ during Heinrich events. Paleoceanography 29, 58-70 (2014).

41. Matear, R. \& Lenton, A. Impact of historical climate change on the Southern Ocean carbon cycle. J. Clim. 21, 5820-5834 (2008).

42. Lecomte, $\mathrm{O}$. et al. Vertical ocean heat redistribution sustaining sea-ice concentration trends in the Ross Sea. Nat. Commun. 8, 258 (2017).

43. Mariotti, V., Paillard, D., Bopp, L., Roche, D. \& Bouttes, N. A coupled model for carbon and radiocarbon evolution during the last deglaciation. Geophys. Res. Lett. 43, 1306-1313 (2016).

44. Hain, M. P., Sigman, D. M. \& Haug, G. H. Distinct roles of the Southern Ocean and North Atlantic in the deglacial atmospheric radiocarbon decline. Earth. Planet. Sci. Lett. 394, 198-208 (2014).
45. Köhler, P., Muscheler, R. \& Fischer, H. A model-based interpretation of lowfrequency changes in the carbon cycle during the last 120,000 years and its implications for the reconstruction of atmospheric $\Delta^{14}$ C. Geochem. Geophys. Geosyst. 7, Q11N06 (2006).

46. Morrison, A. \& Hogg, A. On the relationship between Southern Ocean overturning and ACC Transport. J. Phys. Oceanogr. 43, 140-148 (2013).

47. Carsey, F. Microwave observation of the Weddell Polynya. Mon. Weather Rev. 108, 2032-2044 (1980).

48. Golledge, N. et al. Antarctic contribution to meltwater pulse 1A from reduced Southern Ocean overturning. Nat. Commun. 5, 5107 (2014).

49. Zheng, X. et al. Deepwater circulation variation in the South China Sea since the Last Glacial Maximum. Geophys. Res. Lett. 43, 8590-8599 (2016).

50. Zhang, W. et al. A detailed East Asian monsoon history surrounding the 'Mystery Interval' derived from three Chinese speleothem records. Quat. Res. 82, 154-163 (2014).

51. Menviel, L. et al. Removing the North Pacific halocline: effects on global climate, ocean circulation and the carbon cycle. Deep Sea Res. Part II 61-64, 106-113 (2012).

52. Ronge, T. et al. Radiocarbon constraints on the extent and evolution of the South Pacific glacial carbon pool. Nat. Commun. 7, 11487 (2016).

53. Burke, A. \& Robinson, L. The Southern Ocean's role in carbon exchange during the last deglaciation. Science 335, 557-561 (2012).

54. Pahnke, K. \& Zahn, R. Southern Hemisphere water mass conversion linked with North Atlantic climate variability. Science 307, 1741-1746 (2005).

55. Sikes, E., Elmore, A., Allen, K., Cook, M. \& Guilderson, T. Glacial water mass structure and rapid $\delta^{18} \mathrm{O}$ and $\delta^{13} \mathrm{C}$ changes during the last glacial termination in the Southwest Pacific. Earth. Planet. Sci. Lett. 456, 87-97 (2016).

56. Sabine, C. et al. The oceanic sink of anthropogenic $\mathrm{CO}_{2}$. Science 305, 367-371 (2004).

57. Mikaloff-Fletcher, $\mathrm{S}$. et al. Inverse estimates of anthropogenic $\mathrm{CO}_{2}$ uptake, tranport, and storage by the ocean. Glob. Biogeochem. Cycles 20, GB2002 (2006).

58. Goosse, H. et al. Description of the Earth system model of intermediate complexity LOVECLIM version 1.2. Geosci. Model Dev. 3, 603-633 (2010).

59. Brovkin, V., Ganopolski, A. \& Svirezhev, Y. A continuous climate-vegetation classification for use in climate-biosphere studies. Ecol. Modell. 101, 251-261 (1997).

60. Mouchet, A. The ocean bomb radiocarbon inventory revisited. Radiocarbon 55, 1580-1594 (2013)

61. Berger, A. L., Long term variations of daily insolation and Quaternary climatic changes. J. Atmos. Sci. 35, 2362-2367 (1978).

62. Abe-Ouchi, A., Segawa, T. \& Saito, F. Climatic conditions for modelling the Northern Hemisphere ice sheets throughout the Ice Age cycle. Clim. Past. 3, 423-438 (2007).

63. Kovaltsov, G., Mishev, A. \& Usoskin, I. A new model of cosmogenic production of radiocarbon $14 \mathrm{c}$ in the atmosphere. Earth. Planet. Sci. Lett. 337-338, 114-120 (2012).

64. Roth, R. \& Joos, F. A reconstruction of radiocarbon production and total solar irradiance from the Holocene ${ }^{14} \mathrm{C}$ and $\mathrm{CO}_{2}$ records: implications of data and model uncertainties. Clim. Past. 9, 1879-1909 (2013).

65. Rojas, M. Sensitivity of Southern Hemisphere circulation to LGM and $4 \mathrm{XCO}_{2}$ climates. Geophys. Res. Lett. 40, 965-970 (2013).

66. Thompson, D. \& Solomon, S. Interpretation of recent southern hemisphere climate change. Science 296, 895-899 (2002).

67. Zheng, F., Li, J., Clark, R. \& Nnamchi, H. Simulation and projection of the Southern Hemisphere annular mode in CMIP5 models. J. Clim. 26, 9860-9879 (2013).

68. Sarmiento, J. \& Gruber, N. Ocean Biogeochemical Dynamics 526 (Princeton University Press, Princeton, NJ, 2006).

69. Farneti, R., Delworth, T., Rosati, A., Griffies, S. \& Zeng, F. The role of mesoscale eddies in the rectification of the Southern Ocean response to climate change. J. Phys. Oceanogr. 40, 1539-1557 (2010).

70. Delworth, T. et al. Simulated climate and climate change in the GFDL CM2.5 high-resolution coupled climate model. J. Clim. 25, 2755-2781 (2012).

71. Griffies, S. et al. Coordinated ocean-ice reference experiments (COREs). Ocean Model. 26, 1-46 (2009).

72. Large, W. \& Yeager, S. The global climatology of an interannually varying airsea flux data set. Clim. Dyn. 33, 341-364 (2009).

73. Kidston, M., Matear, R. \& Baird, M. Parameter optimisation of a marine ecosystem model at two contrasting stations in the Sub-Antarctic Zone. DeepSea Res. II 58, 2301-2315 (2011).

74. Oke, P. et al. Evaluation of a near-global eddy-resolving ocean model. Geosci. Model Dev. 6, 591-615 (2013).

75. Ziehn, T., Lenton, A., Law, R. M., Matear, R. J. \& Chamberlain, M. A. The carbon cycle in the Australian Community Climate and Earth System Simulator (ACCESS-ESM1) - Part 2: Historical simulations. Geosci. Model Dev. 10, 2591-2614 (2017). 
76. Law, R. M. et al. The carbon cycle in the Australian Community Climate and Earth System Simulator (ACCESS-ESM1) - Part 1: model description and preindustrial simulation. Geosci. Model Dev. 10, 2567-2590 (2017).

77. Wanninkhof, R. Relationship between gas exhange and wind speed over the ocean. J. Geophys. Res. 97, 7373-7381 (1992).

78. Olsen, A. et al. The Global Ocean Data Analysis Project version 2 (GLODAPv2) - an internally consistent data product for the world ocean. Earth Syst. Sci. Data 8, 297-323 (2016).

79. Hogg, A., Spence, P., Saenko, O. \& Downes, S. The energetics of Southern Ocean upwelling. J. Phys. Oceanogr. 47, 135-153 (2017).

80. Bi, D. et al. ACCESS-OM: the ocean and sea-ice core of the ACCESS coupled model. Aust. Meteorol. Oceanogr. J. 63, 213-232 (2013).

81. Henry, L. et al. North Atlantic ocean circulation and abrupt climate change during the last glaciation. Science 353, 470-474 (2016).

82. Buizert, C. et al. The WAIS Divide deep ice core WD2014 chronology - Part 1: Methane synchronization (68-31 ka BP) and the gas age-ice age difference. Clim. Past. 11, 153-173 (2015).

\section{Acknowledgements}

This project was supported by the Australian Research Council. L. Menviel, K. Meissner, P. Spence and J. Yu acknowledge funding from the Australian Research Council grants DE150100107, DP180100048, DE150100223, FT140100993 and DP140101393 as well as from NSFC41676026. K. Meissner acknowledges support from the UNSW Science Goldstar award. LOVECLIM experiments were performed on a computational cluster owned by the Faculty of Science of the University of New South Wales, Sydney, Australia. MOM5 experiments were performed on the Australian NCI super computer Raijin. Figure 2 was done with the help of Dr. Alex Sen Gupta.

\section{Author contributions}

L.M. designed the study, performed and analysed LOVECLIM experiments. M.C. and R. M. coupled WOMBAT to MOM and calibrated MOM-WOMBAT. P.S. performed MOM-WOMBAT experiments with the help of M.C. P.S. and L.M. analysed MOM-
WOMBAT experiments. L.M. wrote the manuscript with contributions from P.S., J.Y., M.C., R.M., K.M. and M.E.

\section{Additional information}

Supplementary Information accompanies this paper at https://doi.org/10.1038/s41467018-04876-4.

Competing interests: The authors declare no competing interests.

Reprints and permission information is available online at http://npg.nature.com/ reprintsandpermissions/

Publisher's note: Springer Nature remains neutral with regard to jurisdictional claims in published maps and institutional affiliations.

(c) (i) Open Access This article is licensed under a Creative Commons Attribution 4.0 International License, which permits use, sharing, adaptation, distribution and reproduction in any medium or format, as long as you give appropriate credit to the original author(s) and the source, provide a link to the Creative Commons license, and indicate if changes were made. The images or other third party material in this article are included in the article's Creative Commons license, unless indicated otherwise in a credit line to the material. If material is not included in the article's Creative Commons license and your intended use is not permitted by statutory regulation or exceeds the permitted use, you will need to obtain permission directly from the copyright holder. To view a copy of this license, visit http://creativecommons.org/ licenses/by/4.0\%

(C) The Author(s) 2018 